\title{
Vernacular mobile literacies: multimodality, creativity and cultural identity
}

Article

Accepted Version

Albawardi, A. and Jones, H. R. (2020) Vernacular mobile literacies: multimodality, creativity and cultural identity. Applied Linguistics Review, 11 (4). pp. 649-676. ISSN 1868-6311 doi: https://doi.org/10.1515/applirev-2019-0006 Available at https://centaur.reading.ac.uk/81521/

It is advisable to refer to the publisher's version if you intend to cite from the work. See Guidance on citing.

To link to this article DOI: http://dx.doi.org/10.1515/applirev-2019-0006

Publisher: De Gruyter

All outputs in CentAUR are protected by Intellectual Property Rights law, including copyright law. Copyright and IPR is retained by the creators or other copyright holders. Terms and conditions for use of this material are defined in the End User Agreement.

\section{www.reading.ac.uk/centaur}

\section{CentAUR}

Central Archive at the University of Reading

Reading's research outputs online 


\title{
Vernacular Mobile Literacies:
}

\section{Multimodality, Creativity and Cultural Identity}

\author{
Areej Albawardi \\ Imam Abdulrahman Bin Faisal University \\ Rodney Jones \\ University of Reading
}

\begin{abstract}
This paper focuses on how advanced learners of English at a woman's college in Saudi Arabia use Snapchat to communicate with their classmates. It examines not just the way the English language becomes a meaning making resource in these exchanges, but also how English is strategically mixed with photos, drawings, emoji's, and other languages to create meanings, identities, and relationships. The theoretical framework used to understand these strategies is adopted from Scollon and Scollon's (2003) model of 'geosemiotics', an approach to discourse that focuses on how meanings (as well as identities and relationships) are created through the ways semiotic resources are arranged in physical space. The analysis highlights how Snapchat creates opportunities for female learners of English in Saudi Arabia to open up new 'cultural spaces', and how these spaces can facilitate their language learning. At the same time, it is argued, these new 'cultural spaces' are contingent on the various creative ways these learners make use of physical space. Implications for understanding the relationship between creativity and translanguaging are discussed.
\end{abstract}


Keywords: creativity, geosemiotics, gender, language learning, mobility, multimodality, social media, translanguaging

\section{Introduction}

The figure below is from the Snapchat 'story' of a university aged, female learner of English in Saudi Arabia. In it, the author makes use of a range of semiotic resources to express a complex, multi-layered message about her appearance, her feelings, and, ultimately, her social identity (Figure 1).

Insert Fig, 1 here

Figure 1. Eyeliner on fleek

These resources include not just the English language, but also drawings, emojis, fonts and colours, and even her own body. Perhaps the most important thing about the language that she uses is that it is not really understandable apart from the way it is superimposed upon the image. The word 'why' takes its meaning from the circle inscribed above it which calls our attention to the author's dishevelled braiding, with the hasty scrawl in which is it written seeming to reinforce the point, and the phrase below it, 'eyeliner on fleek though' written in neat block letters, takes its meaning from the contrast that it creates with the message above it. And so, despite the fact that this text does not actually involve a lot of words or resemble in any way the kind of English that this student might be expected to produce in her English classes, it does show a sophisticated sense of composition: in particular, an understanding of how to emplace linguistic signs in relation to the physical world and to other semiotic signs. It also shows an understanding of how using certain 
kinds of words or phrases or images in certain ways can also act to emplace a person within a particular physical space and within a particular 'cultural space'. The phrase 'eyeliner on fleek', for example, connects this author to a long line of online makeup tutorials in which the phrase has been used, and ultimately to a six second Vine video by a woman named Peaches Monroee ${ }^{1}$, and the use of the 'sassy girl in pink' emoji similarly connects her to a lineage of female social media users for whom this symbol expresses not so much a meaning as an attitude (Danesi, 2017).

But what is particularly interesting, and particularly creative, about the appropriation of these transcultural social media memes is how the author emplaces them not just within her message but also within the cultural context in which she lives. In many ways, this image is not that different from the kinds of images young women all over the world circulate on their Snapchat stories: it is a selfie. On the other hand, though, it is a selfie which conforms to the social norms of the culture in which the photographer lives that discourages young women from broadcasting pictures of their faces over social media. We might say that the face of the sassy girl in pink and the catchphrase 'eyeliner on fleek' 'stand in' for the face of the photographer, whose own face lies outside the frame of the image.

This article explores vernacular multimodal literacy practices language learners engage in, which, on their surface, may not seem to have much to do with language learning, but which, we argue, reveal the ways they creatively appropriate and mix a range of resources in their everyday lives to enact social identities that have the potential to transcend the social and communicative constraints imposed upon them by the social contexts in which they live.

Much has been written about the vernacular digital literacies of language learners and how these literacies contribute to their construction of transnational identities. The most famous

\footnotetext{
1 'We in dis bitch, finna get crunk, eyebrows on fleek, dafuq.' https://youtu.be/dfBdBpr7KCo
} 
treatments include Lam's (2000) study of a Chinese-American teenager's participation in English fan communities, Black's (2005) exploration of how English language learners use fan fiction websites as a way to practice their English, and Gee (2003) and Steinkuler's (2004) research on the benefits of video games in language learning (for overview see Jones, 2017). There has also been work on how the multimodal and translingual resources characteristic of such literacies can inform more formal literacy events, such as Canagarajah's (2011:401) account of how a female Saudi student's use of emoticons and other multi-sensory cues in her school writing creates opportunities for what he calls 'teachable strategies of translanguaging'.

This idea of 'translanguaging', whether the term is used or not, is a common thread that runs through all of these studies of vernacular digital literacies and language learning, from Lam's observation of how the Chinese-American teenager she studies articulates his unique 'voice' through 'the complex orchestration of multiple modalities through electronic media within a growing diversity of linguistic and cultural affiliations' (Lam 2000: 461), to the inventive ways video gamers mix languages and other semiotic resources in ways that allow them to 'relate, juxtapose, and meld [their] real-world identit[ies] ....and the virtual identit[ies] of the character[s] [they are] playing' (Gee, 2003:120). Central to these studies is the notion that digital media create opportunities for users not just to move easily between different linguistic systems and to easily mix languages and modalities, but also to go beyond them (Garcia \& Li Wei, 2013: 35). As Li Wei (2011:1123) argues, this movement, mixing, and transcendence of semiotic systems has the potential to create a unique 'social space for the multilingual user by bringing together different dimensions of their personal history, experience and environment, their attitude, belief and ideology, their cognitive and physical capacity into one coordinated and meaningful performance'. This 'translanguaging space', in turn, 'has its own transformative power' because it gives rise to 
possibilities for the generation of new identities, new values and new social practices (Garcia \& Li Wei, 2013: 35). 'Translanguaging space', Li Wei (2011: 1234) writes, is 'interactionally created by the individual through strategic use of the social resources, including linguistic resources, that are available to them.' It 'creates a social world in which the actor plays a number of roles and occupies a number of positions... where the individual feels a sense of connectedness with others, and that sense of connectedness has an impact on the social behaviours of the actor and the others concerned.'

All of the studies mentioned above focus on what we might call 'stationary' digital literacies in which users typically spend extended periods of time sitting in front of computer screens engaging in lengthy interactions, reading and writing relatively lengthy texts or playing massively multiplayer online games. The assessment of how digital technologies can impact language learning will obviously be different in the context of mobile applications like WhatsApp and Snapchat in which users depend more on non-verbal resources (such as photographs and emojis) and which may involve only brief snippets of what we might traditionally think of as language: phatic expressions, single words such as 'why?' or formulaic phrases such as 'eyeliner on fleek'. How much language learning is facilitated through the production of such texts is certainly debatable.

But mobile communication does not just change how we think about digital technology as a language learning tool. It also potentially changes how we think about such notions as 'translanguaging space', which, as it is formulated by Li Wei (2011:1225), refers not to 'physical locations or historical contexts only, but...networks of social relations, real or virtual, that are created by individuals through ... shared ...practices for specific social purposes.' While mobile technologies have a way not just of highlighting importance of 'networks' and 'connections', they 
also reassert the importance of the physical spaces people inhabit when they use them. Key to the communicative affordances of these technologies, in fact, are the ways they allow users to move between, mix and link together different physical spaces, in the same way multilinguals move between, mix and transcend semiotic systems, personal histories, identities and practices. Mobile messages such as those circulated through Snapchat take their meaning not just from what they represent but from the way they connect their senders and receivers to particular physical places. As can be seen from the example above, communicating through Snapchat is a kind of 'placemaking' (Schneekloth \& Shibkley, 1995), achieved through the emplacement of particular semiotic signs (including users' own bodies) within various physical spaces. These acts of emplacement situate them within both physical and cultural contexts, and help them to transcend these contexts, creating new 'spaces' for new kinds of learning to occur and new kinds of identities to be constructed.

This paper will attempt to explore the degree to which language learners' creative use of such platforms as Snapchat can enhance language learning though allowing users to utilize physical space as a semiotic resource to open up the metaphorical social, cultural and ideological spaces that Li Wei invokes through the term 'translanguaging space'.

\section{Setting and Data}

The data analysed in this paper come from a larger study which focuses on the digital literacy practices of a group of female university English majors in a woman's college in Saudi Arabia which includes interviews, questionnaires, literacy logs, and examples of participants' messages from WhatsApp and Snapchat (Albawardi, 2017). The data specific to this paper 
consist of 109 Snapchat 'snaps' from participants' Snapchat 'stories' which they agreed to allow the researchers to capture by taking photographs of them with an additional device. ${ }^{2}$

As in many places, Snapchat and other social media platforms do not have a particularly positive reputation among educators and authorities in Saudi Arabia. They are certainly not normally considered to be of any benefit for learning language, and some commentators have claimed that social media has had a negative effect on students' academic performance (AlKhatib and Sabbah, 2008; Alwagait, Shahzad, \& Alim, 2015) and on their ability to acquire good English (Lingwood and Hussein, 2012). Concerns have also been raised about the negative effects of social media on people's social interaction and their ability to engage in meaningful discussions and to form meaningful relationships with others (Al-Haidari, 2015, April 8; Alolyan, 2015; Hashim, Al-Sharqi \& Kutbi, 2016). Finally, some critics have claimed that the use of social media and the values it promotes might be at odds with Arabic and Islamic cultural values (Al-Sharqi, Hashim, \& Kutbi, 2015), especially when it comes to norms of privacy and modesty (Abokhodair \& Vieweg, 2016).

Nevertheless, social media remains extremely popular, especially among Saudi young people. In 2015, Saudi Arabia was ranked $7^{\text {th }}$ in the world for individual social media accounts per individual with an estimated seven accounts per person, and $8^{\text {th }}$ globally in the use of Snapchat (26\% of Saudi teenagers use Snapchat) ('Saudi social media users ranked 7 th in world', 2015, November 14). Although the vast majority of social media users in Saudi Arabia are men ('A virtual revolution...', 2014), women are becoming increasingly visible on platforms like Snapchat in ways that legal and cultural constraints on social interaction would make

\footnotetext{
${ }^{2}$ The data collection was conducted in 2014 before Snapchat altered the programme to make it easier to take screenshots of snaps. In Snapchat, there are two kinds of posts: posts on My Story that last for 24 hours and private posts sent to individual users that last for up to 7 seconds after which they disappear. All snaps collected for this study were from posts on My Story.
} 
difficult in the physical world ('Unshackling themselves', 2014). This increased use of social media among Saudi women and the potential societal tensions it creates adds yet another layer of significance to issues around representation and emplacement when young Saudi women appropriate social practices from global internet culture when using this app. An example of this tension can be seen in a scandal that recently ensued when photos of an unveiled young woman dressed in a short skirt visiting a heritage site in the religiously conservative province of Najd were posted on Snapchat, resulting in her being questioned by the Kingdom's Committee for the Promotion of Virtue and the Prevention of Vice (Weaver \& Mahmood, 2017, July 18).

Interestingly, the focus of the online debate that followed this incident was less on the appropriateness of the woman's dress, and more about the physical/geographical space in which she was photographed. In other words, among the 'new literacies' Saudi women need to learn when managing social media is how to strategically use its affordances for managing emplacement, what is seen and not seen, where, when and by whom.

\section{Theoretical Orientation: Communicating in/with space}

Our approach to analysing the data draws on theories from mediated discourse analysis (Norris \& Jones, 2005; Scollon, 2001) and geosemiotics (Scollon \& Scollon, 2003), perspectives on discourse which focus less on conventional linguistic aspects of meaning making and more on how things like the mode, materiality and emplacement of messages in the physical world contribute to the kinds of social actions people can take, and the kinds of social identities they can assume. Mediated discourse analysis reminds us that semiotic signs and systems are cultural tools (Wertsch, 1994) which allow people not just to make meaning, but to accomplish concrete social actions. Geosemiotics reminds us that, while these tools are semiotic in nature, they also 
invariably involve material instantiations, and that neither their meaning nor their utility for social action can be separated from their materiality and the way they interact with other aspects of the material world, especially space. This materiality, argue the Scollons (2003) is the fundamental basis of the notion of indexicality (Peirce, 1955), the meaning a sign derives from the connection it makes to the context in which it is used. They use a stop sign as an example. The meaning of the word 'stop' and the ability of this word to actually produce the action of stopping is entirely dependent on the way the sign indexes a particular place in the physical world. And this indexicality is a matter of the way the sign itself is emplaced in physical space. A stop sign leaning up against a wall in the office of the Highways Department or displayed in the bedroom of a teenager does not have the same meaning (or produce the same action) as a stop sign emplaced at the intersection of two roads. But geosemiotics takes this notion of indexicality a step further by asking us to attend to the indexical meaning of all signs. 'Whether a sign is an icon, a symbol, or an index,' write the Scollons (2003: emphasis ours) there is a major aspect of its meaning that is produced only through the placement of that sign in the real world in contiguity with other objects in that world.'

While the focus of indexicality in geosemiotics is primarily on what Silverstein (1976) would call 'first order' indexicality, the way semiotic signs are connected to the physical context of their use, the placement of these signs in particular physical contexts in particular ways invariably creates 'second' and 'third order indexicality', the kind of meaning that is made when aspects of the social world beyond the immediate physical context are invoked, aspects such as social identities, social relationships and social values (see Hanks, 2001). Semiotic resources are, after all, cultural tools (Wertsch, 1994), and so their use always connects their users to particular 'cultures' or what Scollon and his colleagues (2012) call 'discourse systems'. The kinds of 
connections that are made, however, are still dependent upon the ways these cultural tools are emplaced in physical space. The picture of the unveiled Saudi woman that caused such a stir when uploaded onto Snapchat would likely not have attracted rebuke had she not been photographed in that particular place, or if the photo had not been broadcast through Snapchat.

Most texts, then, have a rather more complicated relationship to the social world than stop signs. Like the post of the unveiled Saudi woman, they are a mix of multiple semiotic systems (language, dress, architecture, geography) that create connections between multiple discourse systems (local, national and transnational 'cultures'). Most texts, the Scollons (2003: 185) argue, are semiotic aggregates, within which 'multiple, partly overlapping, but nevertheless distinct discourses are operating' simultaneously. The fundamental property of semiotic aggregates, is what they call interdiscursive dialogicality, the way these aggregtes bring different 'discourse systems' into dialogue with each other. The emplacement of the Sassy Girl emoji and the expression 'eyeliner on fleek' superimposed onto the school uniform of a female Saudi University student in the photograph above provokes a dialogue between the global discourse of fashion and femininity and more conservative local discourses of conformity and propriety. It is these moments of dialogue that are central to Li Wei's notion of 'translanguaing space', which, after all, is not just about the 'mixing' of resources, but about the new connections and the new kinds of social relationships made possible through this mixing.

Mobile digital messaging has brought with it new affordances for facilitating these dialogues, opening up new and more complex ways for people to create connections between cultural spaces through the way they enable people to make connections between physical spaces. Wargo (2015) calls the mobile phone a 'cartographic interface' - an interface whose main affordance is its ability to produce not just representational meanings, but indexical 
meanings by allowing people to emplace signs, objects and their own bodies within multiple, overlapping and laminated spaces. Mediated through mobile messaging technologies, geosemiotics - or, as Albawardi (2017) calls it, 'mediated geosemiotics'—is not just a matter of making meaning through the emplacement of signs in physical space, but using signs to configure multiple overlapping spaces.

Over a decade ago, before the advent of the mobile internet, Jones (2005) argued that computer mediated communication allowed people to simultaneously inhabit at least five kinds of spaces: the physical spaces where they sat in front of their computers, the virtual spaces constituted by software (for example chatrooms and IM contact lists), the screen space where objects and signs could be arranged in different configurations, the geographical coordinates they inhabited, and relational space, which involved both the physical and the metaphorical distance between users and their interlocutors. Mobile messaging technologies make available a similar repertoire of spaces with which users can make meaning: there is the physical space where photos are taken, the screen space of the app which functions as a canvas for the arrangement of different kinds of semiotic objects (photos, text, writing, drawing, emojis), the phenomenological space communicated through the embodied perspectives of users as they experience different physical spaces (what we are calling embodied space), relational space, formed through the interpersonal relationships created between the sender and the receiver of messages, and cultural space, formed through the invocation of different 'discourse systems'. What we wish to explore through the analysis of these Snapchat messages sent by female Saudi university English majors is how they are able to use these different spaces as resources for provoking dialogues between the different cultures they inhabit and the different identities that they need to perform at school, at home, and online. 


\section{Analysis}

As we explained above, the affordances of Snapchat allow users to combine images, videos, text, drawings and emojis in complex ways. Other social media platforms also allow for the sharing of pictures, text and videos, but in Snapchat the way these semiotic codes and modes can be combined is unique. Whereas in applications like WhatsApp, different modes and codes are presented sequentially (users might send a message in Arabic, then a message in English, then an image, and then a voice message), in Snapchat multiple modes and codes are presented simultaneously, and their meaning is partially a function of the way they are spatially arranged in relation to one another, and the way they create connections to particular physical spaces. Meaning is also communicated, however, thorough the way users emplace themselves and communicate their experience of being in a particular space or use their bodies as semiotic resources. Finally, Snapchat allows users to invoke different cultural spaces, both through the pictures that they take and the texts they compose, and through the menus of icons and symbols that the app makes available. In a sense, Snapchat is the prototypical translangauging space, enabling the flexible and creative mixture of languages, fonts, semiotic modes, objects, people and places. In their book on translanguaging, García and Li Wei (2013) use the language settings on the iPhone as a metaphor for the difference between code switching and translanguaging. Whereas most mobile apps which use a keyboard construct a code-switching epistemology in which users must change the keyboard to 'switch' languages, Snapchat creates a translingual epistemology, allowing users to combine different kinds of languages and scripts without having to switch between keyboards or apps. As we will show below, the translingual epistemology of Snapchat in the hands of language learners not only allows users to easily combine codes and modes into single messages, but also to combine different orientations towards physical and 
cultural spaces and, in so doing, to enact identities and relationships with their social worlds that foster creativity and learning.

\section{Physical Spaces}

As we argued above, communicating on Snapchat is a kind of 'placemaking', a form of communication in which physical and geographical spaces become resources for communication. Users typically take pictures of the places where they are and send them to friends who are located in different places. First and foremost, what is communicated through a snap is - 'I am here, and this is what being here is like for me.' This sense of connection to physical space can be seen in the example below (Figure 2).

\section{Insert Fig 2 here}

\section{Figure 2. Home sweet home}

Obviously the image depicts the home of the user. But more importantly, it depicts her perspective of returning home from somewhere else. In other words, it creates an implied link between two kinds of spaces -- 'home' and 'not home', and invites the viewer to experience entering a new location (from their own perspective of either being in their own homes or being away from home). In this way, the English idiom 'Home sweet home', itself not a particularly 'creative' use of English, despite being fortified with the unconventional spelling of 'sweeeeet' and the addition of emojis, takes on a special meaning as it is connected to this user, her home, and the sets of practices she shares with her classmates who may be, at the same time, experiencing a similar feeling of returning home after a long day at school. The point we are trying to make here is that the author of this snap had a range of choices to make, not just choices 
regarding linguistic code, spelling, and the choice of font and emojis, but also choices about where to take the picture (she could have taken it inside her house) and choices about how and where to emplace the phrase 'home sweeet home' on to the physical facade of the building.

In many of these images it is not just the geography of the space but also the materiality of space that contributes to the communication of meaning. In the following figure (Figure 3 ) the wet floor and the reflection of the plant on the wet surface for example, serves to reinforce the Arabic sentence: 'Good morning with the smell of rain.' It is as if the smell of rain is semiotically signalled through the layering of texture, colour, text and emojis. It is not just the geographic coordinates of places — but their surfaces and textures that take on semiotic utility.

Insert Fig. 3 here

Figure 3. Good morning with the smell of rain

As can be seen in the above images, the use of physical space as a communicative resource is not just a matter of representing that space, but also a matter of representing the way the photographer is experiencing space. This can also be seen in the following example (Figure 4):

\section{Insert Fig. 4 here}

Figure 4. The last lecture

The user here is not only sharing an image of a cup of coffee. She is making considered choices about what specific objects to include in the frame of the image (coffee, lecture notes, the screen upon which a PowerPoint presentation is playing) in order to communicate where this 
is (her lecture hall) and the practices that she and her classmates receiving this snap engage in. What is most important, however, is the way the image communicates not just the physical space of the classroom, but also the actual place in the classroom where she is sitting.

Much has been written about photographic practices of social media users who often share seemingly trivial objects like plates of food or cups of coffee (see for example Rousseau, 2012). It is important to remember that, when it comes to mobile technology, the meaning of such objects is always tied up with their emplacement in physical space. This is not just a picture of a cup of coffee. It is a picture of a particular spatial experience and a particular social practice in which a cup of coffee played a part

\section{Screen Space}

Another important resource for meaning making in Snapchat is the physical space of the screen upon which users design their messages. In the case of screen space, users often exploit the framing and perspective of the camera and superimpose language, drawings or emojis in relation to the objects they have photographed. In the example below, the participant is sharing a picture of her cup of coffee with an Arabic text superimposed on it which can be translated as 'evening coffee'.

Insert Fig. 5 here

Figure 5. Evening coffee

Objects and bodies (the hand of the photographer holding the coffee) in this snap are strategically emplaced within the screen space. The text is emplaced not just in the middle of the 
screen, but literally inside the cup of coffee, to identify both the beverage and the social practice of 'evening coffee', as well as to give the text prominence. The phrase is followed by an emoji of a musical note which almost seems to be emanating from the coffee, implying the joy the user associates with the practice. At the same time, a black and white filter is applied to the screen which alters the degree of realism of the image (Kress and van Leeuwen, 1996). The relationship between the real world and the image in this snap is not naturalistic; the black and white filter overlays the image with a particular 'mood' or attitude towards what is depicted. The use of filers is a common practice associated with apps such as Snapchat and Instagram, and these photographic affordances provide users a way to use the screen space to create visual effects that communicate their attitude towards the images they are sending or the practice that they represent. Zappavigna, 2016: 285-6) describes how filters can be used to involve nostalgia for past historical periods or previous kinds of media. She writes:

many of these filters, both in terms of their visual effect and naming, evoke 'bygone' eras. For instance, they allow the user to manipulate visual dimensions of the image that invoke older media and conventions (e.g. polaroid photography). 'Retro'-style filters of this kind evoke the physical imperfections of analogue film processing through effects mimicking phenomena such as light leaks and vignetting.... Interestingly, the simulation of these past photographic technologies is not aimed at fidelity but instead represents the 'look of aged photographs as they appear to us in the present' (Bartholeyns, 2014: 60), and this is in keeping with the emphasis that the social stream places on the present and 'real-time' image capture and sharing. 
In other words, these filters provide a resource for users to create connections between present actions and more enduring social practices associated with particular time periods or particular cultural values or memories. The effective use of filters, therefore, requires not just a sense of what appears visually attractive, but how different visual effects communicate complex cultural meanings.

It is also possible to entirely eliminate the image, making the screen itself the primary space for meaning making. For example, the user can hold her finger over the camera, resulting in a black background, thereby both creating a blank canvas for her words and creating implicature through the absence of a background picture. In the image below (Figure 6), for example, the black background functions as both the surface upon which the words can be written and a metaphor for the user's black mood.

Insert Fig. 6 here

Figure 6. Bad mood

This image also illustrates the translingual epistomology of Snapchat, which allows the user to easily combine writing systems (and writing directions) without changing keyboards by using the handwriting function for the Arabic. Here, the Arabic writing both mirrors and elaborates on the English expression and 'sad' emoji: 'I'm tired; I want to graduate', followed by a handwritten 'sad' emoji $=($.

Screen space also allows the user to display other screens within the primary screen of the app. In the following example, the user translanguages through multiple screens:

Insert Fig. \& here 
Figure 7. A screen within a screen

The sequence of snaps as displayed on the two different screens each tells a different story. There is the screen of the sender's laptop on which she is watching a popular Korean television show, with which people receiving these snaps are sure to be familiar. And there is the screen space of Snapchat, which, in the first four images frames the screen of the television show and allows the user to laminate this screen with emojis and Arabic writing which complements the Arabic subtitles that are part of the first screen, and in the last two images serves as a canvas for the sender's metadiscourse on this activity, expressed in English and emojis. In a sense, then, Snapchat allows the user to incorporate her own subtitles into the frame of the television show, as well as to use the affordances of Snapchat to 'reframe' the story into one about why she is watching the show.

The two narratives are not only emplaced in two different screens but also in two different cultural spaces (see below). Posting clips of a Korean show is indicative of the interest in this genre as part of the participants' orientation towards transnational cultural products, and the remarks about the sender's finals ties the story back to local educational practices. This overlapping of cultural spaces, as we will discuss below, is part of what allows these users to construct their hybrid identities as Saudi students and as English majors.

\section{Embodied Spaces}

Similar to other social media platforms, Snapchat allows users a wide range of affordances to manipulate codes and modes in the design of messages. What makes Snapchat different from other platforms is the way it allows senders to use their physical environments and their own bodies as communicative resources. This affordance of Snapchat is one of many 
opportunities which technology provides to allow people to experience their bodies in new and different ways (Jones, 2011). As a result of these affordances, certain practices have become common in Snapchat, such as taking selfies. A selfie is a means to emplace the user's body, or face, in time and space. Embodiment, in Snapchat can also be seen to take place at a nexus of physical space, screen space, interpersonal space and cultural space.

In the example with which this paper began (Figure 1), the sender uses embodied space in several ways. First, the image is a kind of 'selfie' (though unlike those popular in other cultural contexts) in which the user herself is the subject of the photograph, and the photograph acts as a kind of reflexive commentary on her appearance (as are most 'selfies'). Second, the body is used as a background upon which words are written and symbols are placed, the dark surface of the sender's school uniform creating a contrast with the white text emplaced on top of it. Finally, the meaning of this body also comes from the skillful use of space as a communicative resource: from the way the photographer conceals and reveals different parts of her body and creates a certain embodied perspective for the viewer. These embodied spaces invite the viewer to enter into the perspective of the author as she views herself through the mirror of the screen of her mobile phone.

A big part of the literacies involved in using this app, then, is understanding how to use the phenomenological experience of the body as a resource for meaning. In the following example, the user is snapping while physically moving through space to look for food:

Insert Fig. 8 here

Figure 8. Looking for food 
This snap shows how movement in space is expressed through a combination of different semiotic resources including the foot of the user striding forward, the blurred nature of the photograph, suggesting movement, the use of the 'man running' emoji, mirroring the sender's movements, and the choice of language (especially the present continuous tense).

\section{Social/Relational Space}

What is communicated through a snap, however, is not merely (or even primarily) representational. Just as important as what is represented in a snap is the interpersonal relationship that the snap creates between the sender and the receiver, a relationship that is also constructed through the creative layering of different spaces and the emplacement of objects and signs within those spaces. One way this is achieved, as we observed above, is through the affordance of digital photography to allow users to communicate their experience of physical space both by taking a picture of the place they inhabit and communicating their particular perspective of that place through how they hold the camera and frame the image. In Snapchat, the sender is emplaced in the particular space where the snap is taken. Whether the sender chooses to be in the image, i.e. take a selfie, or show others in the snap, there is still an identifiable sender who is usually presumed to be holding the phone when the snap is taken. In 'The Last lecture' example above (Figure 4), the participant is not only inviting the viewer to experience the physical space of that particular classroom but also, by choosing a specific perspective of the camera, creating a particular set of relationships both with the lecturer and with the viewers of the snap, who have presumably experienced similar lectures from similar perspectives. 
Thus, the emplacement of visual elements contributes to the management of social relationships. The perspective chosen by the participant and choices made about what to fit into the screen creates interpersonal space. In Figure 5 (evening coffee) above, showing the participant's hand in the image emphasizes an emplaced as well as embodied experience, and the choice of a vertical angle to capture the cup of coffee is an attempt to involve recipients by allowing them to share the same visual perspective as the author. There is actually no distance between the viewer and the cup or the hand. The relationship between screen space, perspective and interpersonal space can also be seen in the following example:

Insert Fig. 9 here

Figure 9. Life is hard in translation class

The participant in Figure 9 was in a translation lecture when she posted this snap. She took a picture of her desk, notebook and file and wrote in English, 'Life is hard in Translation class', followed by two emojis. What is interesting about this snap is the way the perspective of the photograph is used as a semiotic resource not only to inform the viewer about the physical place where the photograph was taken, but also to construct a relationship with the viewer and to enact a particular social identity. The physical setting of this snap not only affects the choice of code, but also constrains the use of the tool through which this message is being sent. The perspective of the image shows that the participant is positioned behind a desk with a notebook and a file in front of her, fulfilling the role of a student who is in a 'translation class', a context in which, as viewers of this snap will recognise, mobile phones are not permitted. Thus the sender is confronted with a tension between the constraints of the physical space she inhabits and the other social spaces which her mobile phone makes available to her. The participant is actually 
taking a risk to share her feelings and involve her viewers in that particular moment, and the perspective of the photograph communicates that she is trying to take a picture without being noticed. In this way, the constraint imposed on communication in the classroom becomes a resource for communicating with the recipients of the picture, allowing the photographer to claim a transgressive identity and create solidarity with her classmates by inviting them to share in her perspective.

This snap reveals that in Snapchat multiple interaction orders (Goffman, 1983, Scollon and Scollon 2003) can be constructed simultaneously. There is the interaction order of the situation in which the snap is taken, and the interaction order between the sender of the snap and the receiver of the snap. In this picture, the power relationships between the teacher and the student influence how the snap is taken, and at the same time, help to facilitate the communication of a more egalitarian relationship between the sender and receivers. The receivers of the snap immediately recognize why it has been taken this way because of their own experiences in the interaction order of the classroom, and sharing this reinforces the solidarity between sender and receiver because it makes them co-conspirators in the taking of the picture.

\section{Cultural space}

The final spatial dimension we will discuss is cultural space, a dimension which is, in some ways, more abstract than the concrete, material spaces of the screen, the physical environment and the users' bodies discussed above. At the same time, it is important to realize that cultural space is not just dependent on, but created through the representation of these concrete material spaces. A good example of this can be seen in the cultural practice of taking selfies. 
As we mentioned above, one of most popular practices in Snapchat is taking selfies (Charteris, Gregory, \& Masters, 2014). In most cultural contexts the most pervasive semiotic object in Snapchat is the 'self' — represented though a full frontal image of the users' face. A selfie is a means of emplacing the user's body, or face in multiple spaces. Selfies are mainly about 'me' in a particular place in which physical and embodied spaces intersect, but also about communicating an interpersonal space through utilizing perspectives, codes and modes, filters and other screen resources.

The 'selfies' taken by the young Saudi women who participated in this project, however, are in some ways very different from those typically taken by young women in other cultural contexts, due in part to cultural norms which discourage women from broadcasting their unveiled faces on social media. Therefore, several techniques are used to simultaneously participate in the 'selfie culture' of Snapchat and to honour local traditional norms.

One technique employed is the 'half-selfie' (Albawardi, 2017) as illustrated in Figure 1 and in the following example:

Insert Fig. 10 here

Figure 10. Half a selfie

Part of understanding this embodied and emplaced moment is the very fact that this is a moment that is shared and viewed by others via Snapchat. Because images such as the 'half a selfie' take place through Snapchat, there is an established presupposition that what is displayed on the screen is the creation of receivers' already known Snapchat friend, whether that friend is identifiable in snaps or not. In this snap, the physical body is doing the action of taking the selfie, texting and locating the text in the center of the screen. By emplacing the text on the body, the 
participant is claiming ownership of the text which communicates a thought about the world to her Snapchat followers. The use of an English text with a marked spelling, 'lyf' and 'lyk', superimposed onto a traditional Saudi female black gown allows the participant to claim the identities both as a 'hip' English-speaking young person, and as a Saudi female who conforms to 'traditional' apparel. The perspective the participant provides for her viewers creates a particular kind of interpersonal space that can be characterized as intimate or personal. The image of the sender's upper body creates a perspective for the receiver which mimics the space of a personal interaction. At the same time, like a veil, the perspective conceals what might be visible in faceto-face interaction, the sender's face. In other words, by creatively using the affordances of the app which enable her to control what is visible in the physical environment she inhabits, the sender is able to participate in the transnational practice of 'Snapchat selfies' and also to conform to the conservative norms of her local society.

Other strategies for talking 'selfies' were also observed in our data. For example, users sometimes shared selfies that showed the full-frontal image of their faces or other people's faces but used the sketch feature in Snapchat to scribble or write over these faces in order to represent the self but at the same time hide the face, and some users used mirrors to take pictures of the back of their heads. In addition to showing or concealing the face in selfies, the participants in some snaps captured what was going on their faces instead of showing their faces. One prominent topic in our data was images of makeup. Globally, make up is usually tested or shown on the users' face. In our data, however, users typically constructed displays of makeup on the table next to them to suggest the way the makeup appeared on their concealed faces, as in Figure 11 below.

Insert Fig. 11 here 
Figure 11. Make up on table

What was particularly interesting about our data was how these young women adapted the transcultural genre of the selfie to their own cultural context, taking selfies that, if you will, communicated 'selfiness' without violating social norms against woman circulating images of their faces online. And by using these different semiotic aggregates, the users were able to emplace themselves in different cultural spaces and invite one another into their different and overlapping worlds which include the female, Saudi, university, digital and global worlds.

\section{Conclusion}

In this article we have endeavoured to show how young Saudi women use the multimodal and multilingual resources made available in Snapchat to open up what Li Wei (2011) calls 'translanguaging space', a space where multilingual individuals can experiment with their identities and the relationships they have with their peers and with their societies. Such experimentation is particularly important for language learners as they negotiate their place in multiple 'discourse systems'. We have also argued that investigating the kinds of vernacular mobile literacies associated with digital apps like Snapchat provides a unique window onto translanguaging space. Li Wei (2011:1224) writes:

To investigate translanguaging space empirically, and to analyse the creativity and criticality of multilingual practices, requires a paradigm shift, away from frequency and regularity oriented, pattern-seeking approaches to a focus on spontaneous, impromptu, and momentary actions and performances of the individual... 
Snapchat is all about such 'momentary actions and performances.' With it, users are able to create 'moments' which are 'characterised by (their) distinctiveness and impact on subsequent events and 'moments' and, provide 'a reference point or frame' through which 'patterns can be detected'. At the same time, it provides tools through which users can create links between different moments, languages, discourse systems, and identities through linking different physical spaces. Translanguaging, in this case, is not just a matter of moving between and mixing semiotic systems and modalities, but also moving between and mixing concrete physical spaces and layering those spaces in strategic ways. In doing so, the users of this app address both the immediate demands and constraints associated with moments of communicating with their friends and enacting membership in particular peer communities such as fashionistas or English majors studying for exams, and the broader demands and constraints of being Saudi women who are required to uphold certain norms regarding privacy, honour, family reputation and the sanctity of the body (Abokhodair \& Vieweg, 2016:1).

Mobile apps like snapchat provide new ways for identities to be situated and for communication to be occasioned, and require users to develop new literacies involving the emplacement of signs in complex configurations of overlapping space, literacies that language learners are already developing outside of the classroom to manage their identities and their positions in multiple communities. The question remains, what are the implications of these new literacies for classroom teachers. It is important to stress that we are not suggesting that teachers attempt to incorporate apps like Snapchat into their lessons. Indeed, often attempts to domesticate students' out of school practices such as gaming or social media and fit them into the constraints of the classroom can have the result of compromising the very creativity that we wish to cultivate (see for example de Groot, 2017). Rather, what our analysis suggests is that 
vernacular literacies often operate on the fine line between disruption and domestication. Rather than teachers trying to further domesticate technologies, a more productive stance might be to acknowledge the ways technology is used by students to play with and laminate multiple spaces upon each other including the spaces of language classrooms, their homes, the commercial venues where they congregate, and the virtual spaces that they inhabit whose value for them is precisely that they are beyond the supervision of teachers — and how the ways they strategically emplace themselves in these different spaces can create new opportunities for learning.

\section{References}

'A Virtual Revolution: Why social media have a greater impact in the Kingdom than elsewhere' (2014, September 13). The Economist. Retrieved from https://www.economist.com/news/middle-east-and-africa/21617064-why-social-mediahave-greater-impact-kingdom-elsewhere-virtual

Abokhodair, N., \& Vieweg, S. (2016). Privacy \& social media in the context of the Arab Gulf. In Proceedings of the 2016 ACM Conference on Designing Interactive Systems (pp. 672683). New York, NY, USA: ACM.

Al-Haidari, M. (2015, April 8). Social media: Our family relations are in danger! Alriyadh. Retrieved from http://www.alriyadh.com/1037242

Al-Khatib, M. A., \& Sabbah, E. H. (2008). Language choice in mobile text messages among Jordanian university students. SKY Journal of Linguistics, 21, 37-65. 
Al-Menayes, J. (2016). The fear of missing out scale: Validation of the Arabic version and correlation with social media addiction. International Journal of Applied Psychology, $6(2), 41-46$.

Al-Saggaf, Y. (2004). The effect of online community on offline community in Saudi Arabia. The Electronic Journal of Information Systems in Developing Countries, 16, 1-16.

Al-Sharqi, L., Hashim, K., \& Kutbi, I. (2015). Perceptions of social media impact on students' social behavior: A comparison between Arts and Science students. International Journal of Education and Social Science, 2(4), 122-131.

Albawardi, A. (2017). Digital literacy practices of Saudi female university students. PhD Thesis. University of Reading, UK.

Alolyan, A. A. (2015). The perceived impact of the internet on family and social relations in the Kingdom of Saudi Arabia. (Doctor of Philosophy), Manchester Metropolitan University. Retrieved from http://espace.mmu.ac.uk/608781/1/Asma\%20Alolyan\%20thesis\%2014\%204\%2016\%20.pdf

Alwagait, E., Shahzad, B., \& Alim, S. (2015). Impact of social media usage on students academic performance in Saudi Arabia. Computers in Human Behavior, 51, 1092-1097.

Black, R. W. (2005). Access and Affiliation: The literacy and composition practices of Englishlanguage learners in an online fanfiction community. Journal of Adolescent \& Adult Literacy, 49(2), 118-128.

Canagarajah, S. (2011). Codemeshing in Academic Writing: Identifying Teachable Strategies of Translanguaging. The Modern Language Journal, 95(3), 401-417. 
Charteris, J., Gregory, S., \& Masters, Y. (2014). Snapchat 'selfies': The case of disappearing data'. eds.) Hegarty, B., McDonald, j., \& Loke, S.. K., Rhetoric and Reality: Critical perspectives on educational technology, 389-393.

Danesi, M. (2016). The Semiotics of Emoji: The rise of visual language in the age of the Internet. London ; New York: Bloomsbury Academic.

De Groot, F. O. (2017). Integrating out-of-class digital literacy development and English literacy practices with classroom language learning and teaching in Thailand. Unpublished $\mathrm{PhD}$ Thesis, University of Reading, UK.

Garcia, O., \& Wei, L. (2013). Translanguaging: Language, Bilingualism and Education. Balingstoke, UK: Palgrave Pivot.

Gee, J. P. (2003). What video games have to teach us about learning and literacy. New York: Palgrave Macmillan.

Goffman, E. (1983). The interaction order: American Sociological Association, 1982 presidential address. American Sociological Review, 48(1), 1-17.

Hanks, W. F. (2001) Indexicality. In Alessandro Duranti (ed.), Key terms in language and culture (pp. 119-121). Oxford: Blackwell.

Hashim, K., Al-Sharqi, L., \& Kutbi, I. (2016). Perceptions of social media Impact on social behavior of students: A comparison between students and faculty. International Journal of Virtual Communities and Social Networking (IJVCSN), 8(2), 1-11.

Lam, W. S. E. 2000. Second language literacy and the design of the self: A case study of a teenager writing on the Internet. TESOL Quarterly, 34 (3), 457-483.

Jones, R. (2011). C me Sk8: Discourse, technology, and" bodies without organs.". Digital discourse: Language in the new media, 321-339. 
Kress, G. R., \& van Leeuwen, T. (1996). Reading images: The grammar of visual design. London: Routledge.

Lam, W. S. E. (2004). Second language socialization in a bilingual chat room: Global and local considerations. Language Learning \& Technology, 8(3), 44-65.

Li Wei (2011). Moment Analysis and translanguaging space: Discursive construction of identities by multilingual Chinese youth in Britain. Journal of Pragmatics, 43(5), 12221235.

Lingwood, R., \& Hussein, R. F. (2012). Internet use by Jordanian English major students and their perception of internet English. English Linguistics Research, 1(1), p50.

Norris, S., \& Jones, R. H. (2005). Discourse in action: Introducing mediated discourse analysis. London: Routledge.

Peirce, C. S. (1955). Logic as semiotic: The theory of signs. In J. Buchler (Ed.), Philosophical writings of Peirce (pp. 98-119), New York: Dover Publications.

Rousseau, S. (2012). Food and social media: You are what you tweet. Lanham, MD: Rowman Altamira.

Schneekloth, L. H., Shibley, \& G, R. (1995). Placemaking : the art and practice of building communities. New York: Wiley.

Scollon, R. (2001). Mediated discourse: The nexus of practice. London: Routledge.

Scollon, R., \& Scollon, S. W. (2003). Discourses in place: Language in the material world. London: Routledge.

Scollon, R., Scollon, S. W., \& Jones, R. H. (2012). Intercultural communication: A discourse approach (3rd ed.). Chichester: Wiley-Blackwell. 
Silverstein, M. (1976). Shifters, linguistic categories, and cultural description. In K. Basso and H. Selby (Eds.), Meaning in anthropology (pp. 11-55), Albuquerque: University of New Mexico Press..

Steinkuehler, C. A. (2004). Learning in massively multiplayer online games. In Y. B. Kafai, W. A. Sandoval, N. Enyedy, A. S. Nixon, \& F. Herrera (eds.), Proceedings of the sixth international conference of the learning sciences (pp. 521-528). Mahwah, NJ: Erlbaum.

Unshackling themselves. (2014, May 17). The Economist. Retrieved from https://www.economist.com/news/middle-east-and-africa/21602249-saudi-women-aregaining-ground-slowly-unshackling-themselves

Wargo, J. M. (2015). Spatial stories with nomadic narrators: Affect, snapchat, and feeling embodiment in youth mobile composing. Journal of Language and Literacy Computing, $2(1), 47-64$.

Weaver, M. \& Mahmood, M. (2017, July 18). Saudi police question woman accused of wearing 'indecent' clothing. The Guardian. Accessed from https://www.theguardian.com/world/2017/jul/18/saudi-arabia-video-of-indecentlydressed-woman-at-heritage-site-prompts-investigation.

Wertsch, J. V. (1994). The primacy of mediated action in sociocultural studies. Mind, Culture, and Activity, 1(4), 202-208.

Zappavigna M, 2016, Social media photography: construing subjectivity in Instagram images, Visual Communication, vol. 15, 271 - 292. 